TP Periodica Polytechnica Chemical Engineering

59(4), pp. 296-305, 2015

DOI: $10.3311 /$ PPch.7801

Creative Commons Attribution (i)

RESEARCH ARTICLE

\section{Characterization of Rigid Polyurethane Foam Prepared from Recycling of PET Waste}

\author{
Abolfazl Ghaderian ${ }^{1}$, Amir Hossein Haghighi ${ }^{*}$, \\ Faramarz Afshar Taromi ${ }^{3}$, Zizi Abdeen ${ }^{4 * *}$, Ali Boroomand ${ }^{2,5}$, \\ Seyyed Mohammad-Reza Taheri ${ }^{6}$
}

Received 08 November 2014; accepted after revision 26 May 2015

\begin{abstract}
Poly (ethylene terephthalate) (PET) waste bottles were recycled to prepare RPUFs (rigid polyurethane foams) by using propylene glycol (PG) in different glycol/polymer molar ratios. The glycolysis products were characterized, after that, they reacted with poly methylene diphenyl diisocyanate (PMDI) in the presence of blowing, co-blowing and second blowing agents to produce the RPUFs. The prepared foams were characterized and compared to foam that is produced by original polyol. It was found that the glycolysis products have possibility for the fabrication of RPUFs with proper properties depending on the blowing agent type and density, also they have similar thermal stability compared to that one produced by original polyol. This may provide an advantage in the future planning for recycling of PET bottles to enhance the mechanical and thermal properties of $P U$.
\end{abstract}

\section{Keywords}

Recycling, poly (ethylene terephthalate) waste, rigid polyurethane foams, glycolysis, polyester polyols

${ }^{1}$ Young Researchers and Elite Club, Shiraz Branch, Islamic Azad University, Shiraz, Iran

${ }^{2}$ Department of Polymer Engineering, Shiraz Branch, Islamic Azad University, Shiraz, Iran

${ }^{3}$ Department of Polymer Engineering, Amir Kabir university of Technology, Tehran, Iran

${ }^{4}$ Petrochemical Department, Egyptian Petroleum Research Institute, Nasr City, Cairo, Egypt

${ }^{5}$ Department of Chemical Engineering,University of Tehran, Kish International Campus, Kish, Iran

${ }^{6}$ Physics Department, Institute for Advanced Studies in Basic Sciences (IASBS), Zanjan, Iran

*First corresponding author, e-mail: haghighi.ah@gmail.com

** Second corresponding author, e-mail: ziziabdeen@yahoo.com

\section{Introduction}

Poly (ethylene terephthalate) (PET) is a thermoplastic polyester widely used in manufacturing of high-strength fibers, photographic films and soft drink bottles [1]. With increasing PET consumption as packaging material, the effective utilization of PET waste has received wide attention for the preservation of resources and protection of the environment [2]. Since PET waste does not create hazards to the environment, its volume and cost of landfilling are very high. However, several methods have been proposed for recycling waste PET [3-7]. Generally, different methods for the chemical recycling of PET could be categorized in five main branches including: 1) glycolysis, 2) methanolysis, 3) hydrolysis, 4) ammonolysis and 5) aminolysis [8]. It is suggested that the most attractive method is chemical glycolysis into the corresponding monomers or raw chemicals that could be reused for the production of plastics or other advanced materials [9]. The glycolysis method makes it possible to employ very low amounts of reactants as well as application of lower temperatures and pressures in contrast with other methods such as supercritical methanol and thermal degradation [3-7], while hydrolysis under acidic or basic conditions may cause corrosion and pollution problems $[10,11]$. Glycolysis involves the insertion of olefin-glycol within PET chains to synthesis bis (2-hydroxyolefin) terephthalate, which is a substrate for PET synthesis. The glycols usually used for PET glycolysis are ethylene glycol (EG), diethylene glycol (DEG), propylene glycol (PG) and dipropylene glycol (DPG). However, EG has been reported as the most reactive olefinglycol for PET glycolysis [12, 13]. The glycolysis product can be used in the synthesis of unsaturated polyester resins, urethane oils [14], dimethacrylated oligoesters, epoxy resins [15], polymer concretes [16, 17] and rigid polyurethane foams [18]. RPUFs are commonly available heat insulation materials with the lowest thermal conductivity among foamed polymers used commercially [1, 19]. These foams are used for example for outer wall insulation of apartment houses, factory shops, office rooms, cold stores and pipelines [20]. The broad application is the result of their very good heat insulation properties, low density and relative ease of specific properties modification 
Table 1 List of PET glycolysis products

\begin{tabular}{ccccccc}
\hline Product code & $\begin{array}{c}\text { Glycol } \\
\text { type }\end{array}$ & $\begin{array}{c}\text { Glycol/PET } \\
\text { molar ratio }\end{array}$ & $\begin{array}{c}\text { Glycol/PET } \\
\text { weight ratio }\end{array}$ & Catalyst & $\begin{array}{c}\text { Catalyst/PET } \\
\text { weight ratio }\end{array}$ & Temperature $\left({ }^{\circ} \mathrm{C}\right)$ \\
\hline PG2.52m & PG & 2.52 & 1 & $\mathrm{Zn}\left(\mathrm{O}_{2} \mathrm{CCH}_{3}\right)_{2}$ & 0.5 & $200-210$ \\
PG2m & PG & 2 & 0.79 & $\mathrm{Zn}\left(\mathrm{O}_{2} \mathrm{CCH}_{3}\right)_{2}$ & 0.5 & $200-210$ \\
PG1m & PG & 1 & 0.396 & $\mathrm{Zn}\left(\mathrm{O}_{2} \mathrm{CCH}_{3}\right)_{2}$ & 0.5 & $200-210$ \\
\hline
\end{tabular}

depending on the use as well as on adjusting technology of production and application in the place of use. Isocyanates, polyols, foaming and auxiliary agents are the main components for polyurethane foams synthesis. Polyester polyols are an important raw material for the production of insulation panels [21]. These foams derive their excellent flammability performance from the high content of aromatic groups which results from high aromaticity polyester polyols. In some regions, polyester polyols' applications are increasing for the same reason as well as for their relatively low cost. The latter is ultimately connected to the origin of aromatic polyester polyols which are produced from recycled PET bottles, fibers, and x-ray film sheets, or DMT process waste. Azim et al. glycolyzed PET wastes using trimethylol propane and pentaerytheriol to produce hydroxyoligomers to producing RPUFs with a density of range $55-65 \mathrm{~kg} / \mathrm{m}^{3}$. They made separation and purification for solvent and glycolysis agent by using a very expensive procedure that consume a lot of time [22]. This work, primarily discusses a potential use of the recycled PET products in preparation of RPUFs without separation and purification of solvent and glycolysis agent. The amount ratio of glycols/ PET on PET glycolysis process was studied. The glycolysis products are characterized using GPC, FTIR and viscometry analysis methods. The characteristics of RPUFs were examined by FTIR, SEM, TGA, thermal conductivity coefficient and compressive strength, moreover, their density. The properties of foams were compared with that foam made with original polyol.

\section{Experimental}

\subsection{Materials}

Post consumer PET beverage bottles were crushed to small pieces after washing them with acetone and methanol to removing an adhesive and other materials. PG and zinc acetate were obtained from Panreac Co. The required material to produce RPUFs such as, PMDI, activators and surfactant agent were commercial grades and were used as received. But with respect to cyclopentane, dichloroethane, and all materials used for analysis, were purchased from Merck Co., and were used as received. FMHC and FMR11 foams that were produced by Urethane Co (Iran). are commercial and a very common. They were used for comparison with prepared samples in this work. FMHC and FMR11, have HCFC-141B and R11 as blowing agents, respectively. Also, URONOLE 210R, and URONOLE
$220 \mathrm{~W}$ are used as polyols, respectively that include additives. PMDI is used with an amount of $32 \% \mathrm{NCO}$.

\subsection{Method}

\subsubsection{Glycolysis of PET wastes}

PET wastes were initially immersed in $1 \%(\mathrm{w} / \mathrm{v})$ sodium hydroxide solution for $1 \mathrm{~h}$ to remove surface impurities and subsequently rinsed with water and dried in an oven at $80^{\circ} \mathrm{C}$. The pre-washed PET and the propylene glycol PG, at different molar ratios of PG/PET, as, 1/1, 2/1 and 2.52/1 respectively, in the presence of $0.5 \%(\mathrm{w} / \mathrm{w})$ zinc acetate were glycolysed. The glycolysis reactions were conducted in a 1 liter three-necked reactor equipped with a reflux condenser, a thermometer and a mechanical steel stirrer in an oil bath in nitrogen gas atmosphere for $15 \mathrm{~min}$. in initial time of the reaction, at 200-210 ${ }^{\circ} \mathrm{C}$ for about 4 hours. Upon completion of the reaction, the glycolysed products were allowed to cool down to the room temperature under nitrogen atmosphere, Table 1. A schematic of used procedure for the glycolysis of waste PET is depicted in Scheme 1.

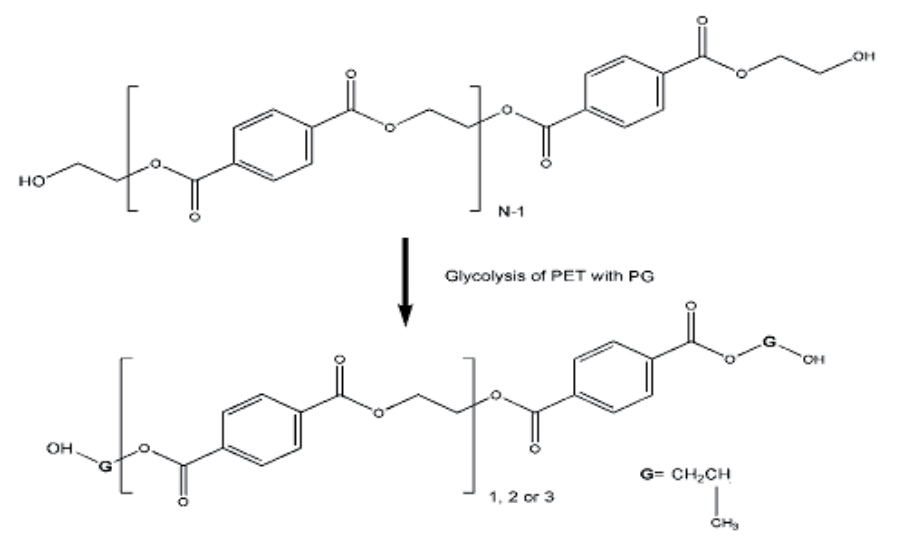

Scheme 1 Schematic of Waste PET glycolysis process using PG as glycols.

\subsubsection{Preparation of RPUFs}

RPUFs were produced in a two steps. First, the prepared polyol was mixed with triethyl amine (TEA) and dibutyltin dilaurate (DBTDL) as catalysts as well as silicone surfactant and the blowing agent. The prepared mixture was allowed to mix for about one minute at a stirring rate of $2000 \mathrm{rpm}$ to obtain a homogenous resin. Afterward, PMDI was added to the prepared polyol mixture and was allowed to stir with a 
constant stirring rate of $2000 \mathrm{rpm}$ for about 10 seconds. Subsequently, the prepared mixture was discharged into an open mold $\left(15 \times 15 \times 7 \mathrm{~cm}^{3}\right)$ for free-rise foams preparation process. The foams were removed after $30 \mathrm{~min}$ and allowed to condition at room temperature for $16 \mathrm{~h}$ before further characterization. About 10 weight $\%$ of PMDI more than Stoichiometries ratio was used for the completion of the reaction. The basic formulation used for the synthesis of RPUF is presented in Table 2. And, simultaneous with expanding the reaction time and after two weeks the core density of foams was determined.

Table 2 Chemical formulation used for the synthesis of RPUFs

\begin{tabular}{cc}
\hline Ingredients & Amount (parts by weight) \\
\hline Polyester polyol & 100 \\
Cyclopentane & 20 \\
Silicon surfactant & 3 \\
DBTDL & 0.4 \\
TEA & 0.4 \\
Dichloroethane & $50 \%$ w/w of cyclopentane \\
Water & $12 \%$ w/w of cyclopentane \\
PMDI & Stoichiometric $+10 \%$ \\
\hline
\end{tabular}

\section{Characterization}

The structure of the products was confirmed by using a Nicolet IR-100 FTIR spectrometer. The specimens were prepared in the form of $\mathrm{KBr}$ pellet. The hydroxyl number $(\mathrm{OH}$ Number) of the glycolysis products was measured in terms of $\mathrm{mg} \mathrm{KOH} / \mathrm{g}$. The measurement method was as follows: $0.5 \mathrm{~g}$ of the prepared sample was accurately weighted and added to 10 $\mathrm{ml}$ of pyridine and acetic anhydride solution (pyridine/acetic anhydride $=88 / 12$ : volume ratios) in a round bottom flask. The flask was equipped with a vertical reflux condenser. The mixture was stirred at the boiling point of water for about 2 hours, and then it was cooled to the room temperature and hydrolyzed by $100 \mathrm{ml}$ of chilled water. The resulting solution was titrated against $0.5 \mathrm{~N} \mathrm{KOH}$ using phenolphthalein as the indicator. The hydroxyl number of samples was calculated from the difference between the $\mathrm{KOH}$ consumed amount of the sample and the control sample according to the following equation:

$$
\text { OH number }=\frac{\left(V_{s}-V_{b}\right) N 56.1}{W}
$$

Where, $V_{\mathrm{s}}, V_{\mathrm{b}}, N$ and $W$ are the volume of $\mathrm{KOH}$ used for the sample (ml), the volume of $\mathrm{KOH}$ used for the control sample $(\mathrm{ml})$, the normality of $\mathrm{KOH}$ solution and the weight of the sample, respectively. The intrinsic viscosity of glycolysis products was calculated without purification in the presence of dichloro acetic acid at $25^{\circ} \mathrm{C}$. In this research, GPC was used to determine average molecular weight and molecular weight distribution of glycolyzed product. The instrument used was Agillent
1100, which included a Refractometer Index Detector (RID) and a set of three high resolution PL gel $10 \mu \mathrm{m}$ Agillent columns $\left(500,10^{3}, 10^{4} \AA\right)$. THF was used as the solvent with a flow rate of $1 \mathrm{ml} / \mathrm{min}$, while monodisperse polystyrene was used as the reference. Also, the density of the RPUFs was measured according to ASTM D-1622. The size of the specimen used for density calculations was $30 \times 30 \times 30 \mathrm{~mm}^{3}$. To normalize the density results, the density of five specimens per each of the foam was calculated and the results were averaged. The morphology of the RPUF samples was studied with AIS 2100 SEM that was made by Seron. The samples were cut as parallel to the rise direction of foams and were coated by the gold before scanning. Compressive strength in $10 \%$ deformation test was performed according to ASTM D 1621 by device of Galdabini 1890. The size of the specimen was $30 \times 30 \times 30 \mathrm{~mm}^{3}$, and the speed of crosshead movement was $3.00 \mathrm{~mm} / \mathrm{min}$. Thermogravimetric Analysis (TGA) of the samples under air atmosphere was carried out on a TA Instruments (Thermal Analysis 2000). The samples were heated from room temperature to 600 ${ }^{\circ} \mathrm{C}$ at a rate of $10^{\circ} \mathrm{C} / \mathrm{min}$. The apparent thermal conductivities were determined using an ANACON model 88. The size of the specimen was $100 \times 100$ with thickness $15-30 \mathrm{~mm}$.

Table 3 Material forms and structural characteristics of glycolysis products

\begin{tabular}{cccc}
\hline Product name & Form & $\begin{array}{c}\text { OH Number } \\
(\mathrm{mgKOH} / \mathrm{g})\end{array}$ & $\begin{array}{c}\text { Intrinsic Viscosity } \\
(\mathrm{dl} / \mathrm{g})\end{array}$ \\
\hline PG2.52m & Viscous liquid & 600 & 0.082 \\
PG2m & Pasty & 570 & 0.092 \\
PG1m & Solid & 327.9 & 0.115 \\
\hline
\end{tabular}

\section{Results and discussion}

\section{Structure and material forms of glycolysis products}

Material forms and appearance of glycolysis products were different from solid to liquid, according to molar ratio of glycol /PET, as shown in Table 3. Wherever, by using the PG/ PET ratios, the products (PG2.52m, PG2m and PG1m) were transparent with a light brown-green color, turned into a milky viscous material over a period of time. And, the product turns into a solid material over cooling down to the room temperature with respect to $1 / 1$ molar ratio of $\mathrm{PG} / \mathrm{PET}$. As a result of increasing the PG/PET ratio, the molecular weight was decreased with increasing in the $\mathrm{OH}$ number. It is necessary to mention that, after the glycolysis reaction was performed, the free glycols were not separated for decreasing viscosity of glycolyzed products, since viscosity is an important factor to produce foam. Due to the presence of free glycols in the final product, hydroxyl value of glycolyzed products was higher than that hydroxyl value of glycolyzed products in the literature, but in accordance with the literature, hydroxyl value of products is increasing with the increase of ratio of the glycol/ PET. For all of the glycolysis products, the hydroxyl numbers 


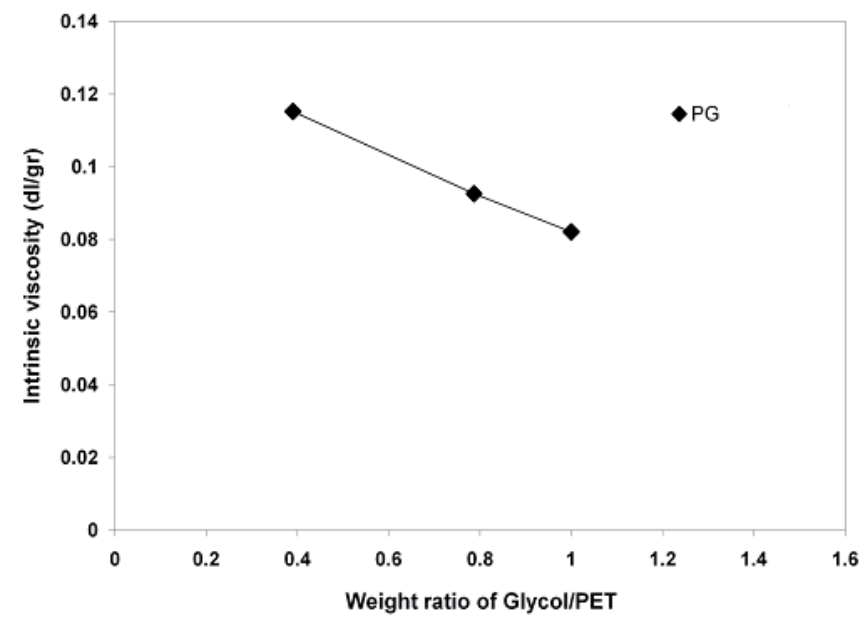

Fig. 1 Viscosity of glycolysis products.

Table 4 Calculated characteristics of terephthalic acid diesters

\begin{tabular}{ccc}
\hline Products & \multicolumn{2}{c}{ Products synthesized from PG } \\
\hline Properties & OH Number $(\mathrm{mgKOH} / \mathrm{g})$ & Molecular weight $(\mathrm{g} / \mathrm{mol})$ \\
Monomer & 397.9 & 282 \\
Dimer & 236.7 & 474 \\
Trimer & 168.5 & 666 \\
\hline
\end{tabular}

increased as the glycol/PET molar ratios increased, but their viscosity and molecular weight decreasing as a result of increasing in the depolymerization of PET. The presence of unreacted glycols leads to lower viscosity of glycolyzed products. The viscosity of glycolyzed products has been depicted in Fig. 1 , and revealed that the PG1m product sample could not be used for the production of RPUFs, unsaturated polyester resin or other final products due to its high viscosity and solidify in the room temperature. Only, PG2m and PG2.52m were used in the production of RPUFs. Molecular weights and $\mathrm{OH}$ numbers of the diester of terephthalic acid which could be produced using PG are calculated and presented in Table 4, according to the procedure described in the literature [23]. It should be mentioned that results in Table 4 are for $\mathrm{N}=1,2$ and 3 in Scheme 1. Clearly, the $\mathrm{OH}$ numbers of glycolysis products, increase as the molecular weights of the products decreased. It should be mentioned that the main purpose of this study was to produce RPUFs, so, the polyol viscosity is an important factor in this process. According to Tables 3 and 4, the hydroxyl values of glycolysis products were greater than calculated $\mathrm{OH}$ numbers of terphthalic acid's diesters due to the presence of free glycols in the mixture. It was notified that the glycolysis of PET under high pressure conditions resulted in shorter melting time of PET flakes and formation of homogenous liquid. However, these conditions also resulted in an increase in the amount of side reactions compared to atmospheric conditions [22]. Therefore, the glycolysis of PET in a sealed reactor resulted in a PET
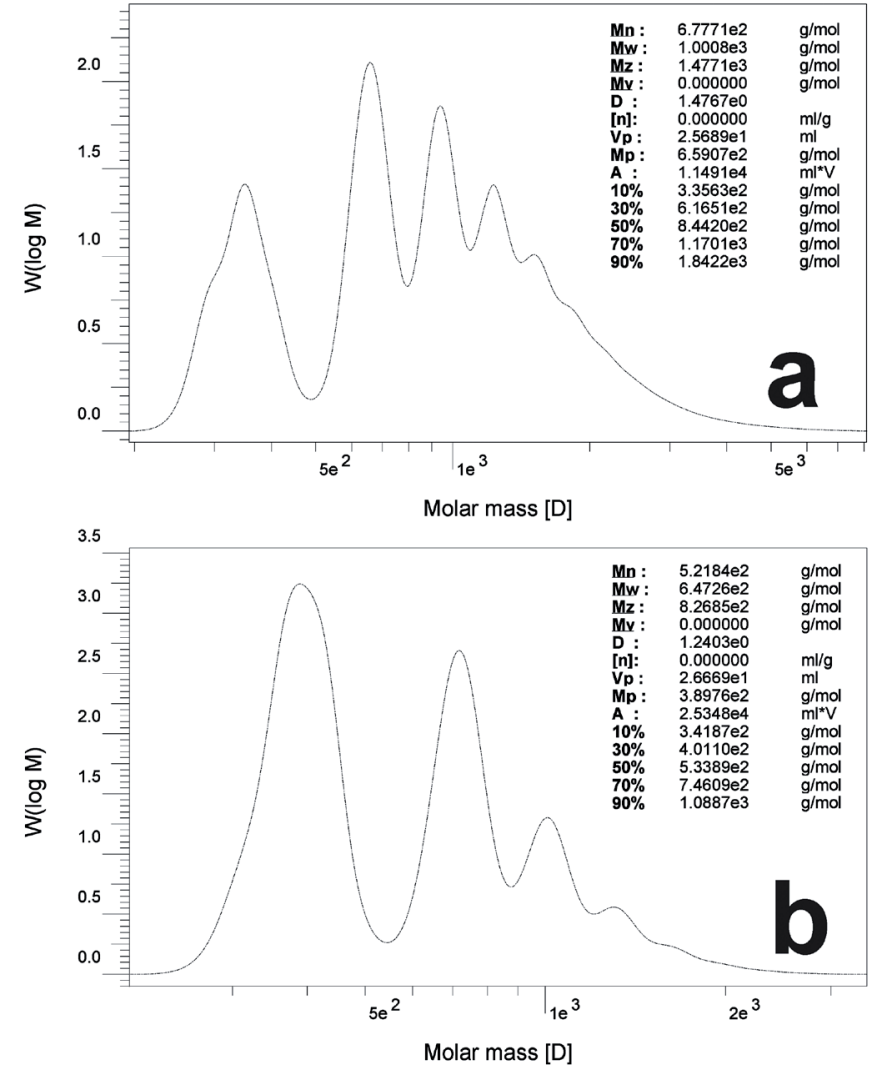

Fig. 2 GPC spectra of glycolysis products prepared using PG; (a) PG1m and (b) PG2.52m.

Table 5 Molecular weights and PDI of glycolysis products

\begin{tabular}{cccc}
\hline Product name & $\mathrm{M}_{\mathrm{n}}(\mathrm{g} / \mathrm{mol})$ & $\mathrm{M}_{\mathrm{w}}(\mathrm{g} / \mathrm{mol})$ & $\mathrm{PDI}$ \\
\hline PG2.52m & 521.8 & 647.2 & 1.24 \\
PG2m & 576.6 & 887.3 & 1.54 \\
PG1m & 677.7 & 1000.8 & 1.48 \\
\hline
\end{tabular}

melting time reduction and formation of a homogenous liquid compared to the reactor under atmospheric conditions. For example, the dissolution time of $\mathrm{PG} 2 \mathrm{~m}$ reduced from $80 \mathrm{~min}$ to about $35 \mathrm{~min}$ in a sealed reactor. It should be mentioned that the pressure of glass reactor was about 0.1 bar that is a low pressure for PET glycolysis under pressure. This condition was selected to a large reduction of PET dissolution time as well as side reactions, compared to PET glycolysis under common conditions with under high pressure. On the other hand, it was observed that the glycolysis products synthesized using PG in the molar ratio of 2.52 in about 4 hours had the same weight and numberaverage molecular weights, Table 5 and Fig. 2, compared to the reported glycolysis products in the same conditions synthesized in about 5 hours and in the atmospheric pressure [24]. It can be seen, in Table 5, with increasing of proportion Glycol/PET, both numerical average molecular weight $\left(\mathrm{M}_{\mathrm{n}}\right)$, and average molecular weight $\left(\mathrm{M}_{\mathrm{w}}\right)$ of glycolyzed product have decreased. In addition to this, the molecular weight distribution has become narrower that it shows more oligomers with the same molecular 
weight have produced. Also in Fig. 2 in all of molecular weight graphs, a large peak was observed under $500 \mathrm{~g} / \mathrm{mol}$ that by comparison with the molecular weights in Table 4, the presence of dimers confirm. The peak in the region of 650-750 confirms the presence of trimers. When we investigate the graphs and their area under the curves we understand that the proportion of dimmers is more than that of trimers and oligomers. With increasing in Glycol/PE proportion, area under the curves in lower molecular weight increase that is the interesting point about area under the curves in GPC graphs. Moreover, the number and area under the curves in terminal of graphs that show higher molecular weight, were become lower that it confirms the amount of degraded PET have decreased with increasing the proportion of Glycol/PET. These results that are related to PG2.52m and PG1m clearly can be seen in Fig. 2.

Moreover, glycolysis of PET in a sealed reactor resulted in a more reduced molecular weight product compared to products obtained in the atmospheric pressure. Also, the reactor pressure was higher in the early stages of the glycolysis process due to the evaporation of glycols. After this step, the reactor pressure decreased and reached to a stable pressure. FTIR spectroscopy was used to confirm the depolymerization of PET, the formation of oligoesters and formation the RPUFs. Also, it was used to study of the difference between the structures of foam prepared from PET and that was made from original polyol. The molecular structures of glycolyzed PET were estimated by FTIR spectroscopy. Figure $3(a, b)$, show the comparative FTIR spectra of glycolysis products obtained by glycolysis with $\mathrm{PG} 2 \mathrm{~m}$ and PG2.52m, respectively. Bands from $-\mathrm{C}=\mathrm{O}$ stretching and stretching vibration of C-O which appear at $1720 \mathrm{~cm}-1$ and $1275 \mathrm{~cm}^{-1}$ respectively, are a key bands that confirmed ester bond formation during the glycolysis of PET. This can be compared with used glycols FT-IR spectrum which does not contain any band around $1750 \mathrm{~cm}-1$ or $1275 \mathrm{~cm}^{-1}$. Band around $3400 \mathrm{~cm}-1$ is due to the free hydroxyl group presents in glycolyzed PET oligoesters. The presence of this peak confirms

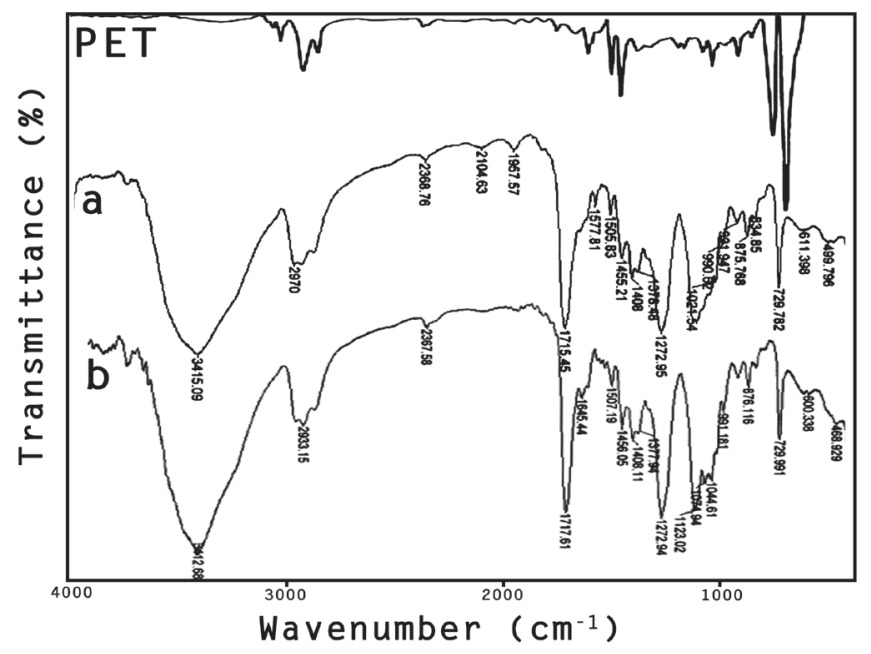

Fig. 3 FTIR spectra of glycolysis products ; PET, PG2.52m a) and b) PG2m.

the successful glycolysis of PET because the FTIR spectrum of PET do not have such a peak and also, the characteristic C-O vibrations and stretching vibration of $\mathrm{C}-\mathrm{O}$ bands of PET were shifted at1000 to $1300 \mathrm{~cm}^{-1}$ and a new ester was formed. The peaks around 2950 and $2880 \mathrm{~cm}^{-1}$, were assigned to the stretching vibrations of $\mathrm{C}-\mathrm{H}$ bands in the structure of methyl and methylene groups. FT-IR spectra show the bands around 1375 and $1455 \mathrm{~cm}^{-1}$ of bending vibration of methylene groups in the polyol chains. Furthermore, the peaks at 1124 and $1078 \mathrm{~cm}^{-1}$ corresponding to a $\mathrm{C}-\mathrm{O}$ group of ether primary and secondaryhydroxyl end-groups in the structure of PG. The different types of the RPUFs samples: FP2.52CyDc (a) and FMHC(b) were shown in the FT-spectra, Fig. 4(a-b). The functional groups in polyurethane can be detected through the existence of the amide (-NH) stretching vibration around $3500 \mathrm{~cm}^{-1}$, urethane carbonyl $(\mathrm{C}=\mathrm{O})$ at $1722 \mathrm{~cm}^{-1},-\mathrm{CH} 2$ around $2927 \mathrm{~cm}^{-1},-\mathrm{CNH}$ around $1523 \mathrm{~cm}^{-1}$ and $\mathrm{C}-\mathrm{O}-\mathrm{C}$ around $1218 \mathrm{~cm}^{-1}$. Other characteristic bands, the $\mathrm{NH}$ deformation signal around $1523 \mathrm{~cm}^{-1}$ of isocyanurate (resulting from reactions between isocyanate and urethane groups) [25], aromatic ester stretching at 1216

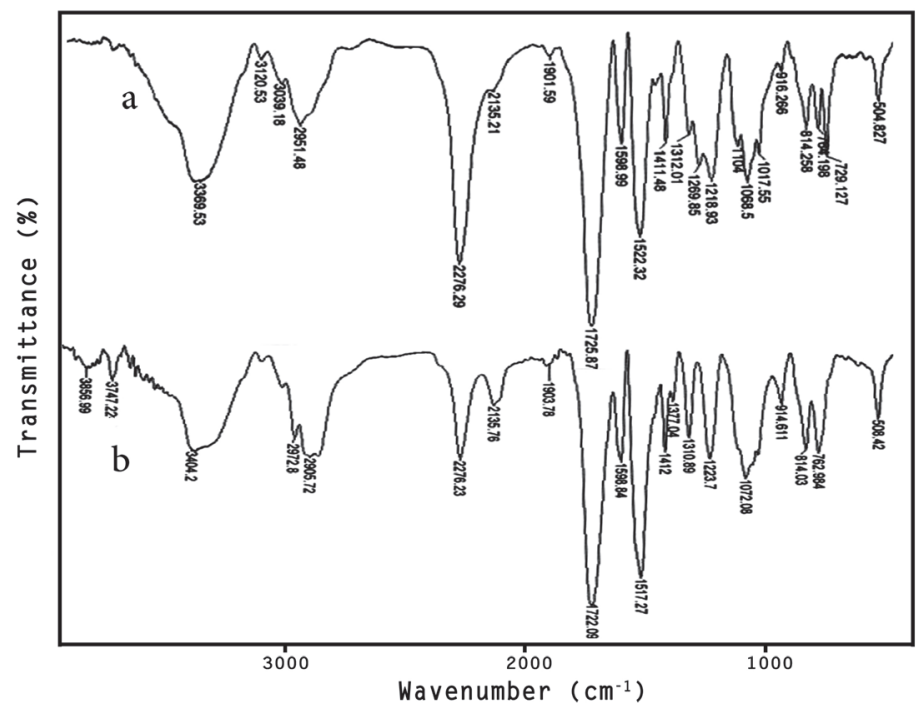

Fig. 4 FTIR spectra of the produced foam samples: FP2.52CyDc (a) and FMHC (b). 
Table 6 Characterization of RPUFs with different blowing agent

\begin{tabular}{|c|c|c|c|c|c|}
\hline Name of RPUFs & Density $\left(\mathrm{kg} / \mathrm{m}^{3}\right) \pm 0.2$ & Mixed time (s) $\pm 2 \mathrm{~s}$ & Cream time $(\mathrm{s}) \pm 2 \mathrm{~s}$ & Gel time $(s) \pm 2 s$ & Tack free time $(\mathrm{s}) \pm 2 \mathrm{~s}$ \\
\hline $\mathrm{FP} 2.52 \mathrm{Cy}$ & 22.24 & 8 & 36 & 70 & 94 \\
\hline FP2.52Cy1.25 & 29.67 & 8 & 25 & 45 & 70 \\
\hline FP2.52CyDc & 34.4 & 8 & 27 & 55 & 75 \\
\hline $\mathrm{FP} 2.52 \mathrm{CyW}$ & 23.88 & 8 & 23 & 40 & 65 \\
\hline FP2Cy & 33.2 & 8 & 32 & 92 & 124 \\
\hline FP2CyW & 30.7 & 8 & 29 & 80 & 120 \\
\hline FP2CyDc & 40.7 & 8 & 38 & 106 & 130 \\
\hline FMR11 & $24-26$ & - & - & - & - \\
\hline
\end{tabular}

F: foam, P: propylene glycol, 2.52 and 2: molar ratios of PG/PET, Cy: cyclopentane, Dc: dichloroethane, W: water, 1.25: isocyanate index

and $1064 \mathrm{~cm}^{-1}$ and $\mathrm{CH}$ deformations of aromatic groups in the range of 800 to $600 \mathrm{~cm}^{-1}$ are also noted in the spectrum. The presence of a large signal at $2258 \mathrm{~cm}^{-1}$ indicates that residual (unreacted) isocyanate still exists in the system [26], which was expected since an isocyanate index equal to 1.10 was used in the foam formulation. The production foams from PG2m and PG2.52m, were used cyclopentane, dichloroethane and water as a main, secondary and co-blowing agents, respectively. We use other blowing agent for enhanced of low compressive strength properties of producing foams. Also, the isocyanates index was used higher than in the primary index for FP2.52Cy. The density and reaction times of foams (RPUFs) using different blowing agent and polyols mixed with PMDI were reported in Table 6. The time stages for forming the foaming without a catalyst for polyol and in the presence of cyclopentane were shown in Fig. 5. Foams made from PG2.52m have shorter reaction times than that of the PG2m, due to lower viscosity and molecular weight since, they enhanced the flow ability and also increase the reactivity. These reaction times decreased, by adding the catalysts, as shown in Fig. 5. It was found that, the density of FP2.52Cy1.25 is higher than that of the FP2.52Cy, since PMDI increased with the same amount of cyclopentane. While, the increase in the amount of PMDI in FP2.52CyW, make its density is lower than that, of the FP2.52Cy1.25 and is a nearly similar to FP2.52Cy one. This was attributed to producing of $\mathrm{CO}_{2}$ gas as a result of the reaction of water with PMDI. The density of foam with cyclopentane was increasing with adding of dichloroethane because of, the boiling point of dichloroethane is higher than those of the cyclopentane and water. As a result, the reaction times for foam with dichloroethane are shorter than that of others, while these times for foam with water are shorter; where the reaction of water with PMDI was produced a heat caused reduced for these times. The density of foams made PG2m is higher than those of the foams with PG2.52m, due to higher viscosity and lower free PG in comparison with the PG2.52m.

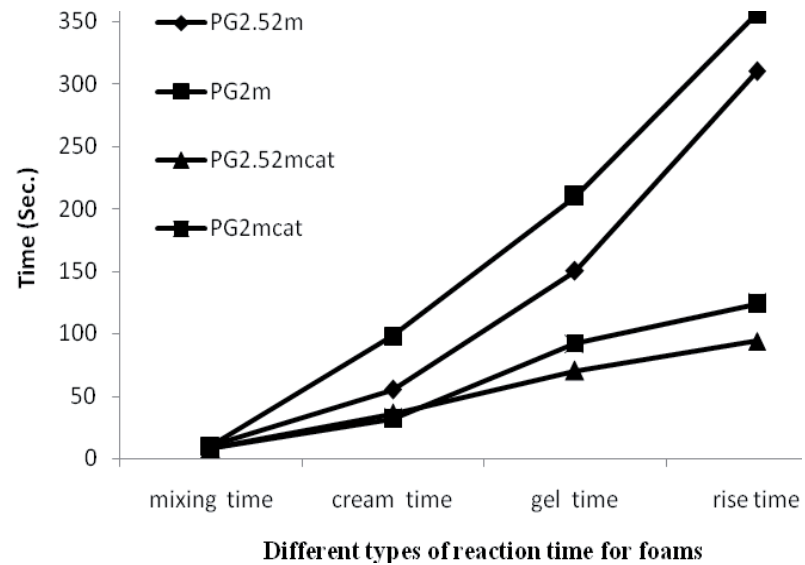

Fig. 5 The foaming times in the presence of cyclopentanefor both polyols and without catalyst.

\section{Compressive strength of foams (RPUFs)}

Compressive strength and modulus in parallel to and perpendicular to the rise direction of foam at $10 \%$ compression were measured and reported in Table 7 . The most important factor has an effect on the compressive strength is the density, where, it increased with increasing in density in the same formulations. Therefore, the foams were prepared with polyol at PG/PET molar ratio of $2 / 1$, have a higher compressive and modulus with a same blowing agent. By comparing FP2.52Cy1.25 with FP2.52CyW, it was shown that, they have a different density, although, they have the same strength. FP2.52CyW has a lower density as a result of formation of $\mathrm{CO}_{2}$ gas, but it has the same strength causing the formation of urea linkage at reacting of water with PMDI. It was appeared from Table 7, with adding dichloroethane and water or with changed isocyanate index, compressive strength and modulus of foams increased than that of the foam was prepared by using cyclopentane. Foams were prepared by using dichloroethane have a high density due to their higher boiling point and molecular weight than cyclopentane. And so, this high density increased the strength and modulus in two directions. Also, the modulus and compressive strength, parallel to the rise 
Table 7 Modulus and compressive strength of foams (RPUFs)

\begin{tabular}{|c|c|c|c|c|c|}
\hline \multirow[t]{2}{*}{ Name of RPUFs } & \multirow[t]{2}{*}{ Density $\left(\mathrm{kg} / \mathrm{m}^{3}\right)$} & $\begin{array}{l}\text { Compressive strength (MPa) } \\
\qquad 0.001\end{array}$ & $\begin{array}{l}\text { Modulus (MPa) } \\
\quad \pm 0.01\end{array}$ & $\begin{array}{l}\text { Compressive strength (MPa) } \\
\qquad \pm 0.001\end{array}$ & $\begin{array}{c}\text { Modulus (MPa) } \\
\pm 0.01\end{array}$ \\
\hline & & \multicolumn{2}{|c|}{ Parallel to the rise direction } & \multicolumn{2}{|c|}{ perpendicular to the rise direction } \\
\hline FP2.52Cy & 22.24 & 0.08 & 1.12 & 0.05 & 0.66 \\
\hline FP2.52Cy 1.25 & 29.67 & 0.11 & 2 & 0.06 & 0.67 \\
\hline $\mathrm{FP} 2.52 \mathrm{CyDc}$ & 34.4 & 0.15 & 2.82 & 0.08 & 1.06 \\
\hline FP2.52CyW & 23.88 & 0.11 & 1.86 & 0.07 & 0.77 \\
\hline $\mathrm{FP} 2 \mathrm{Cy}$ & 33.2 & 0.1 & 1.89 & 0.68 & 1.22 \\
\hline $\mathrm{FP} 2 \mathrm{CyW}$ & 30.7 & 0.134 & 2.04 & 0.08 & 1.02 \\
\hline FP2CyDc & 40.7 & 0.176 & 2.69 & 0.14 & 1.96 \\
\hline FMR11 & $24-26$ & 0.12 & 1.86 & 0.09 & 0.55 \\
\hline
\end{tabular}

Table 8 K-factor and cell dimension of foams (RPUFs)

\begin{tabular}{cccc}
\hline Name of RPUFs & Density $\left(\mathrm{kg} / \mathrm{m}^{3}\right)$ & $\begin{array}{c}\text { K-factor }(\mathrm{W} / \mathrm{m} . \mathrm{K}) \\
\pm 0.0001\end{array}$ & Mean cell size $(\mu \mathrm{m})$ \\
\hline FP2.52Cy & 22.24 & 0.0296 & $332.2 \pm 96.2$ \\
FP2.52Cy1.25 & 29.67 & 0.0199 & $328.3 \pm 61$ \\
FP2.52CyDc & 34.4 & 0.0223 & $480.1 \pm 69$ \\
FP2.52CyW & 23.88 & 0.0297 & $421.6 \pm 111.5$ \\
FP2Cy & 33.2 & 0.0283 & $301 \pm 58.3$ \\
FP2CyDc & 40.7 & 0.0231 & $318.3 \pm 71.2$ \\
FP2CyW & 30.7 & 0.0263 & $322.3 \pm 34.3$ \\
FMR11 & $24-26$ & 0.0212 & $445.4 \pm 85.1$ \\
\hline
\end{tabular}

direction, have higher values than those, perpendicular to, due to the cell orientations in the foam rise direction. It is necessary to mention that a lower compressive strength values of FP2.52Cy or FP2Cy may be causing a plasticizer effect for cyclopentane to tend to be soluble in the polyurethane matrix that with adding other blowing agent. This defect was treated.

\section{Thermal conductive coefficient}

Table 8, shows the K-factor and mean cell size in the perpendicular to the rise direction of foam. This Table shows that the FP2.52Cy1.25 has a lower K-factor than that of the FP2.52Cy, because of the FP2.52Cy1.25 has a lower cell dimension and high cell structure isotropy in comparison with those of the FP2.52Cy, as clear in Fig. 6 (a, b). Also, a lower K-factor of FP2.52Cy1.25 than that of the FMR11 is due to the lower of its cell size and cell uniform that leads to radiative contribution to heat transfer and produce lower $\mathrm{K}$-factor, in accordance with Table 8, and Fig. 6 (a, b). Nevertheless, FP2CyW has a lower cell size than that of FMR11; it has a higher K-factor. Since, the higher thermal diffusivity coefficient of $\mathrm{CO}_{2}$ was substituted with air that has a higher K-factor than that of the $\mathrm{CO}_{2}$. From the Table 8, it was observed that, the cell size was increased with the decreased in the density of foam in the same formulation. This is due to the FP2 foams have a higher density, with a lower cell size that, leads to decrease in K-factor. But, it was noticed that, in Fig. 6b, in, despite decreased of cell size in FP2CyDc with a comparison to that of the FP2.52CyDc, they have the nearly same K-factor. This may due to relatively uniform cell dimensions or high cell structure isotropy and higher of closed cell content in FP2.52CyDc with respect to FP2CyDc in addition, a lower viscosity of FP2.52CyDc than that of the FP2CyDc, causing to the better process ability. Although it was expected that, the foams were blowing with cyclopentane (FP2.52Cy and FP2Cy) have a low of K-factor because of highly non-uniform cell dimensions; they have a higher K-factor in comparison to other foams, Fig. $6(a, b)$.

The thermal stability of material reflected the ability of its chemical structure to resist chain termination and chain 


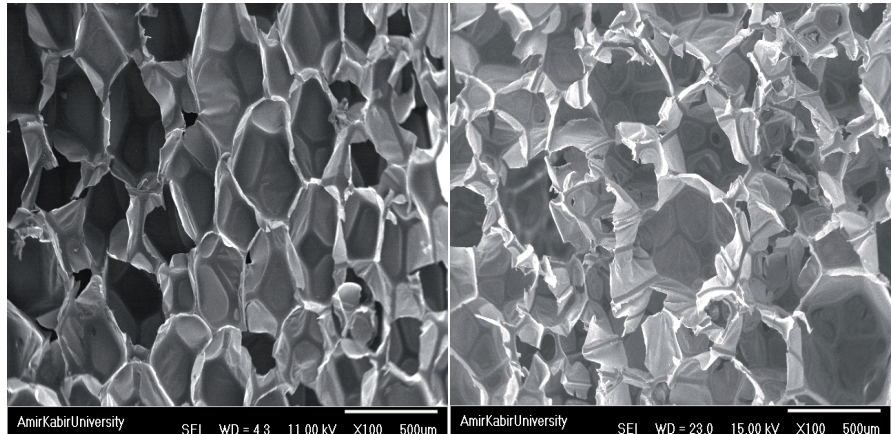

FP2.52Cy1.25

FP2.52Cy

Fig. 6a SEM micrographs of RPUF samples blown with cyclopentane.

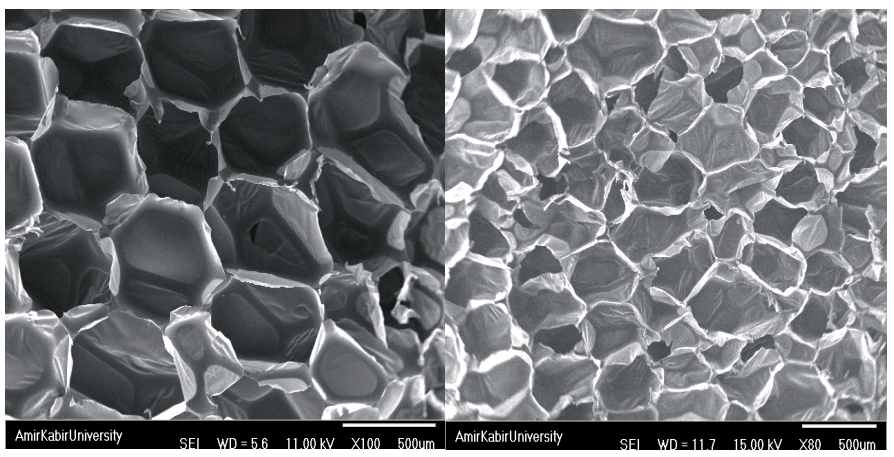

FP2.52CyDc

FP2CyDc

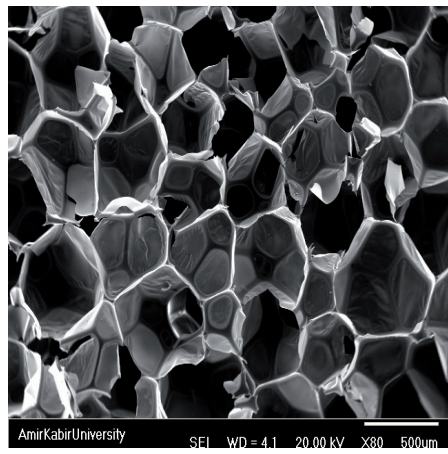

FMR11

Fig. 6b SEM micrographs of RPUF samples blown with cyclopentane and dichloroethane (FP2.52CyDc, FP2CyDc) and foam made Urethane Co. (FMR11).

movement which were caused by heating. One of the important variables which control the thermal stabilization of a polymer is the basic materials which made up the foam that are the polyol and isocyanate. TGA was used to analysis the decomposition behavior of producing foams, FP2.52CyW(a), FMHC(b) and FP2.52Cy1.25(c), synthesized with glycolyzed products obtained from PET waste, Fig. 7. It was proposed that the thermo-oxidative degradation of RPUFs is primarily a degradation process, which starts at about $190-205^{\circ} \mathrm{C}$, and the second decomposition was started at $250-300{ }^{\circ} \mathrm{C}$, and reached to $420-450^{\circ} \mathrm{C}$ that is related to burn of remain ash [27-28]. Where, these experiments were done in air atmosphere. During the burning, oxygen reacts with carbon's ash and produce $\mathrm{CO}_{2}$ gas that it caused a decrease in the weight of the sample. The amount of remain ash reached lower than $24 \%$ and this was related to the groups with high thermal stability like
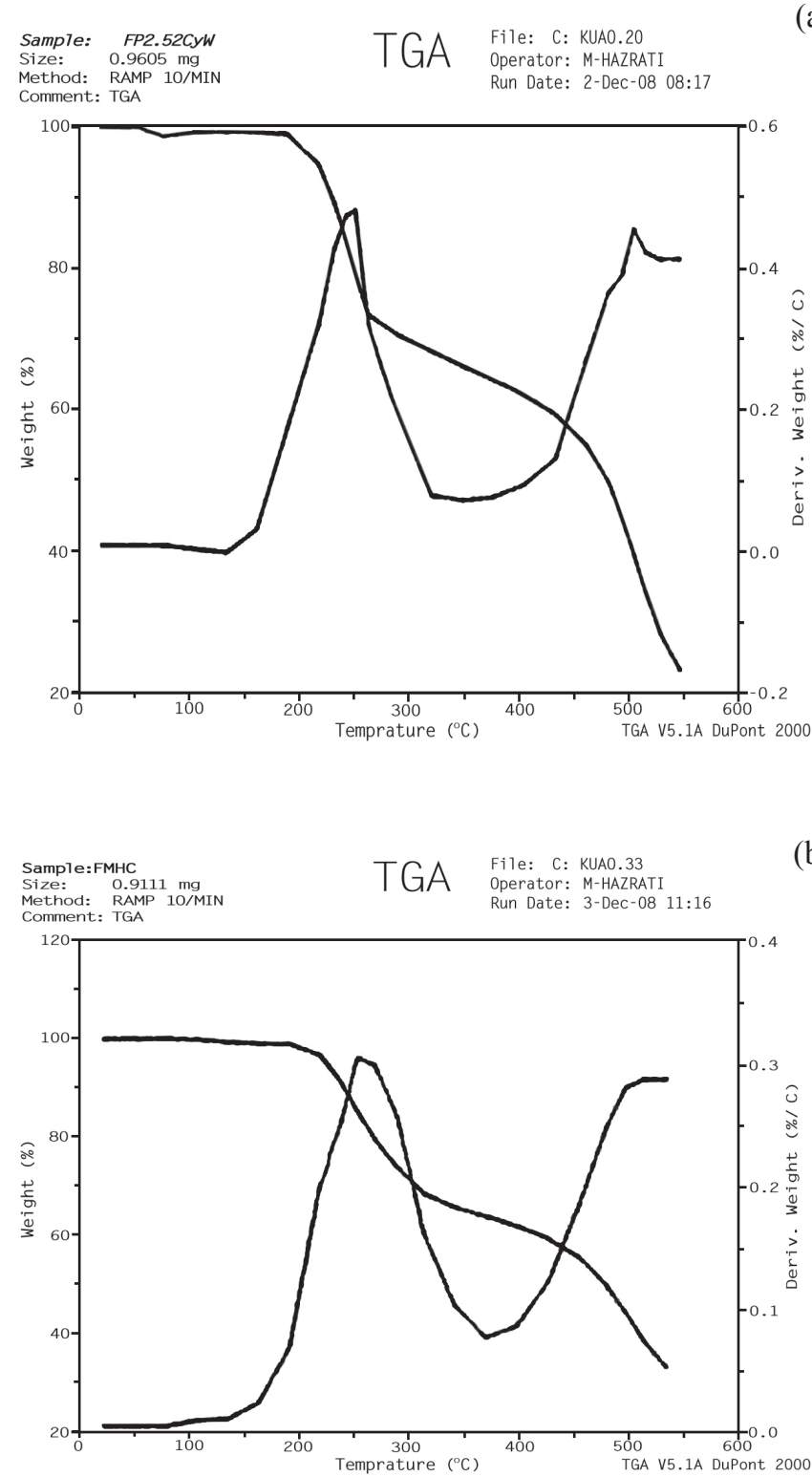

(b)

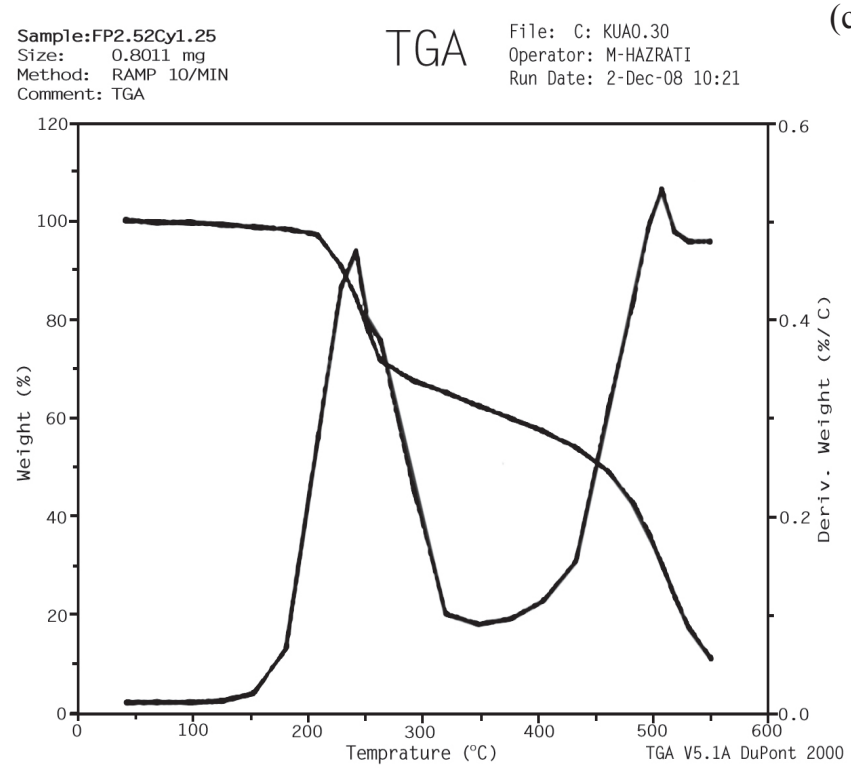

Fig. 7 TGA of FP2.52CyW (a), FMHC (b) and FP2.52Cy1.25 (c) foams. 
allophanate, urea, biurea and so on. Because of the reaction occurred in the room temperature and lack of active catalyst for isocyanate termination, the second decomposition, was not related to isocyanurate decomposition. According to Fig. 7, the higher percent weight of FP2.52CyW ash compare with FP2.52Cy1.25 is due to its high presence of the aromatic group in both polyol and isocyanate. The produced foams, especially FP2.52CyW, have the same thermal stability [27-28] compared with the sample that is produced by Urethane Co.

\section{Conclusions}

Waste PET flakes were depolymerized by using different molar ratio of PG/PET to produce oligomers with a low molecular weight, reacted with PMDI in presence blowing agent to produce different types of PU foams with a high thermal stability, high compressive strength and modulus. The effects of the different molar ratios of glycol/PET on glycolyzed products have been described. GPC results showed that a high portion of oligomers are monomer, dimmer and trimmer, and a lower portion of oligomers had a higher molecular weight. The viscosity of glycolyzed products decreased with an increase in the ratio of glycol/PET in glycolysis processes. Moreover, the PET glycolysis reaction in a sealed reactor led to a reduction of PET flakes dissolution time and increase in the degree of PET depolymerization. The density, compressive strength, modulus, thermal stability and the thermal conductivity coefficient of foams were affected by the molar ratio of glycol/PET and blowing agent. So, it was possible to produce a rigid polyurethane foams by using glycolysis products of waste PET with properties similar to that produced by the foams with original polyol.

\section{Acknowledgments}

Thanks to all members of Department of Polymer Engineering, Shiraz Branch, Islamic Azad University, Shiraz, Iran, Department of Polymer Engineering, Amir Kabir University of Technology, Tehran, Iran and Department of Petrochemical, Egyptian Petroleum Research Institute, Nasr City, Cairo, Egypt, for great effort.

\section{References}

[1] Karayannidis, G. P., Achilias, D. S., George, P. K., Dimitris, S. A. "Chemical Recycling of Poly(ethylene terephthalate)." Macromolecular Materials and Engineering. 292 (2). pp. 128-146. 2007.

DOI: 10.1002/mame.200600341

[2] Ghaemy, M., Mossaddegh, K. "Depolymerisation of poly(ethylene terephthalate) fibre wastes using ethylene glycol." Polymer Degradation and Stability. 90 (3). pp. 570-576. 2005. DOI: 10.1016/j.polymdegradstab.2005.03.011

[3] Kim, B. K., Hwang, G. C., Bae, S. Y., Yi, S. C., Kumazawa, H. "Depolymerization of polyethylene terephthalate in supercritical methanol." Journal of Applied Polymer Science. 81 (9). pp. 2102-2108. 2001. DOI: 10.1002 app.1645
[4] Yang, Y., Lu, Y. J., Xiang, H. W., Xu, Y. Y., Li, Y. W. "Study on methanolytic depolymerization of PET with supercritical methanol for chemical recycling." Polymer Degradation and Stability. 75 (1). pp. 185-191. 2002. DOI: 10.1016/s0141-3910(01)00217-8

[5] Takeshi, S., Idzumi, O., Tsutomu, S., Katsuto, O., Satoshi, Y., Yoshihiro, T. "Recovery of constituent monomers from polyethylene terephthalate with supercritical methanol." Polymer Journal. 32 (2). pp. 178-181. 2000. DOI: $10.1295 /$ polymj.32.178

[6] Chiu, S. J., Cheng, W. H. "Thermal degradation and catalytic cracking of polyethyleneterephthalate." Polymer Degradation and Stability. 63 (3). pp. 407-412. 1999. DOI: 10.1016/s0141-3910(98)00121-9

[7] Chiu, S. J., Cheng, W. H. "Promotional effect of copper chloride on the thermal degradation of poly(ethylene terephthalate)." Journal of Analytical and Applied Pyrolysis. 56 (2). pp. 131-143. 2000.

DOI: 10.1016/s0165-2370(00)00087-5

[8] Chen, C. H. "Study of glycolysis of poly(ethylene terephthalate) recycled from postconsumer soft-drink bottles. III. Further investigation." Journal of Applied Polymer Science. 87 (12). pp. 2004-2010. 2003. DOI: 10.1002/app.11694

[9] Guoxi, X. B., Maixi, L., Chen, S. "Study on depolymerization of waste polyethylene terephthalate into monomer of bis(2-hydroxyethyl terephthalate)." Polymer Degradation and Stability. 87 (1). pp. 117-120. 2005. DOI: 10.1016/j.polymdegradstab.2004.07.017

[10] Kao, C. Y., Cheng, W. H., Wan, B. Z. "Investigation of alkaline hydrolysis of polyethylene terephthalate by differential scanning calorimetry and thermogravimetric analysis." Journal of Applied Polymer Science. 70 (10). pp. 1939-1945. 1998. DOI:10.1002/(sici)10974628(19981205)70:10<1939::aid-app8>3.0.co;2-g

[11] Gamze, G., Tuncer, Y., Saadet, O., Murat, O. "Hydrolysis of waste polyethylene terephthalate and characterization of products by differential scanning calorimetry." Thermochimica Acta. 404 (1-2). pp. 193-205. 2003. DOI: 10.1016/s0040-6031(03)00160-6

[12] Achilias, D. S., Redhwi, H. H., Siddiqui, M. N., Nikolaidis, A. K., Bikiaris, D. N., Karayannidis, G. P. "Glycolytic depolymerization of PET waste in a microwave reactor." Journal of Applied Polymer Science. 118 (5). pp. 3066-3073. 2010. DOI: 10.1002/app.32737

[13] Lirong, Z., Jie, G., Jianzhong, Z., Fengping, Y. "Hydrolysis of poly(ethylene terephthalate) waste bottles in the presence of dual functional phase transfer catalysts." Journal of Applied Polymer Science. 130 (4). pp. 2790-2795. 2013. DOI: 10.1002/app.39497

[14] Pardal, F., Tersac, G. "Reactivity of polyesters in glycolysis reactions: Unexpected effect of the chemical structure of the polyester glycolic unit." Polymer Degradation and Stability. 91 (11). pp. 2809-2812. 2006. DOI: 10.1016/j.polymdegradstab.2006.05.015

[15] Saravari, O., Vessabutr, B., Pimpan, V. "Synthesis of urethane oils from waste poly(ethyleneterephthalate) bottles." Journal of Applied Polymer Science. 92 (5). pp. 3040-3045. 2004. DOI: 10.1002/app.20266

[16] Kosmidis, V. A., Achilias, D. S., Karayannidis, G. P. "Poly(ethylene terephthalate) Recycling and Recovery of Pure Terephthalic Acid. Kinetics of a Phase Transfer Catalyzed Alkaline Hydrolysis." Macromolecular Materials and Engineering. 286 (10). pp. 640-647. 2001. DOI:10.1002/14392054(20011001)286:10<640::aid-mame640>3.0.co;2-1

[17] Glatzer, H. J., Doraiswamy, L. K. "Rate enhancements due to autocatalysis and heterogenization in phase transfer catalysis: a comparative study." Chemical Engineering Science. 55 (21). pp. 5149-5160. 2000. DOI: 10.1016/s0009-2509(00)00139-1 
[18] Oku, A., Hu, L.-C., Yamada, E. "Alkali decomposition of poly(ethylene terephthalate) with sodium hydroxide in nonaqueous ethylene glycol: A study on recycling of terephthalic acid and ethylene glycol." Journal of Applied Polymer Science. 63 (5). pp. 595-601. 1997.

DOI: 10.1002/(sici)1097-4628(19970131)63:5<595::aid-app7>3.0.co;2-p

[19] Vaidya, U. R., Nadkarni, V. M. "Unsaturated polyester resins from poly (ethylene terephthalate) waste-mechanical and dynamic mechanical properties." Industrial \& Engineering Chemistry Research. 27 (11). pp. 2056-2060. 1988. DOI: 10.1021/ie00083a016

[20] Suh, D. J., Park, O. O., Yoon, K. H. "The properties of unsaturated polyester based on the glycolyzed poly(ethylene terephthalate) with various glycol compositions." Polymer. 41 (2). pp. 461-466. 2000.

DOI: 10.1016/s0032-3861(99)00168-8

[21] Chaudhary. S., Surekha, P., Kumar, D., Rajagopal, C., Roy, P. K. "Microwave assisted glycolysis of poly (ethylene terepthalate) for preparation of polyester polyols." Journal of Applied Polymer Science. 129 (5). pp. 2779-2788. 2013. DOI: 10.1002/app.38970

[22] Abdel Azim, A. A., Atta, A. M., El-Ghazawy, R. A. "Synthesis of rigid polyurethane foams from recycled poly(ethylene terephthalate) waste." Cellular Polymers. 25 (1). pp. 35-48. 2006.

[23] Vaidya U. R., Nadkarni, V. M. "Polyester Polyols from Glycolyzed PET Waste: Efect of Glycol Type on Kinetics of Polyesterification." Journal of Applied Polymer Science. 38 (6). pp. 1179-1190. 1989.

DOI: 10.1002/app.1989.070380615
[24] Yoshioka, M., Nishio, Y., Saito, D., Ohashi, H., Hashimoto, M., Shiraishi, N. "Synthesis of biopolyols by mild oxypropylation of liquefied starch and its application to polyurethane rigid foams." Journal of Applied Polymer Science. 130 (1). pp. 622-630. 2013. DOI: 10.1002/app.39167

[25] Chaeichian, S., Pourmahdian, S., Afshar Taromi, F. "Synthesis of Unsaturated Polyester Resins from PET Wastes: Effect of a Novel Co-catalytic System on Glycolysis and Polyesterification Reactions." Designed Monomers \& Polymers. 11 (2). pp. 187-199. 2008.

DOI: $10.1163 / 156855508 \times 298080$

[26] Rivera-Armenta, J. L., Heinze, Th., Mendoza-Martínez, A. M. "New polyurethane foams modified with cellulose derivatives." European Polymer Journal. 40 (12). pp. 2803-2812. 2004.

DOI: 10.1016/j.eurpolymj.2004.07.015

[27] Corcuera, M. A., Rueda, L., Fernandez d'Arlas, B., Arbelaiz, A., Marieta, C., Mondragon, I., Eceiza, A. "Microstructure and properties of polyurethanes derived from castor oil." Polymer Degradation and Stabiliry. 95 (11). pp. 2175-2184. 2010.

DOI: 10.1016/j.polymdegradstab.2010.03.001

[28] Xu, Z., Tang, X., Zheng, J. "Thermal Stability and Flame Retardancy of Rigid Polyurethane Foams/Organoclay Nanocomposites." PolymerPlastic Technology and Engineering. 47 (11). pp. 1-6. 2008.

DOI: $10.1080 / 03602550802391607$ 